\title{
"O USO DO SMARTPHONEÉ UM BOM COMEÇO": ESTUDO DAS SOCIABILIDADES JUVENIS EM CONTEXTO PEDAGÓGICO
}

\author{
EdGARD LEITÃo DE ALBUQUERQUE NETO ${ }^{1}$ \\ VANDERLAN FRANCISCO DA SILVA ${ }^{2}$
}

\begin{abstract}
RESUMO
Este artigo discute as sociabilidades entre jovens estudantes mediadas pelas tecnologias digitais de informação e comunicação, bem como esse novo estilo de vida on-line interfere nas relações estabelecidas no contexto escolar. A presente pesquisa de campo foi desenvolvida nos anos de 2018 e 2019 a partir de observação minuciosa do cotidiano dos estudantes numa escola pública de Ensino Médio no estado da Paraíba. Para isso, selecionamos 73 interlocutores, sendo 46 do gênero feminino e 27 do gênero masculino. A análise dos dados revelou que se produzem lacunas entre as sociabilidades juvenis nas redes digitais e as práticas pedagógicas no ambiente escolar, estimulando comportamentos de resistências dos estudantes frente às atividades presenciais em sala de aula, na mesma medida em que os jovens expressam desejos de que as aulas off-line possam ser mais dinâmicas por meio da utilização das tecnologias digitais.
\end{abstract}

PALAVRAS-ChAVE

Tecnologias digitais; Escola; Jovens estudantes.

\section{"THE USE OF SMARTPHONE IS A GOOD START": STUDY OF YOUTH SOCIABILITIES IN ONLINE AND} OFFLINE SPACES

\begin{abstract}
This article discusses the sociability among young students mediated by digital information and communication technologies, as well as how this new online lifestyle interferes in the relationships established in the school context. This field research was developed in the years 2018 and 2019 from a detailed observation of the daily lives of students in a public high school in the state of Paraíba. For this, we selected 73 interlocutors, 46 female and 27 male. Data analysis revealed that gaps are produced between youth sociabilities in digital networks and pedagogical practices in the school environment, stimulating resistance behaviors of students towards face-toface activities in the classroom, to the same extent that young people express desires that offline classes can be more dynamic through the use of digital technologies.
\end{abstract}

\section{KEYWORDS \\ Digital Technologies; School; Young students.}

\section{"L'USAGE DU SMARTPHONE EST UN BON DÉBUT": ÉTUDE DES SOCIABILITÉS DES JEUNES DANS LES ESPACES EN LIGNE ET HORS LIGNE}

\footnotetext{
${ }^{1}$ Doutor em Ciências Sociais com área de concentração em sociologia pelo Programa de PósGraduação em Ciências Sociais da Universidade Federal de Campina Grande (PPGCS-UFCG).

2 Professor de Antropologia da UFCG e docente do Programa de Pós-Graduação em Ciências Sociais da mesma universidade. Doutor em Ciências Sociais pela Universidade Paris V (Sorbonne). Líder do Grupo de Pesquisa SOCIATOS - Sociabilidades e Conflitos Contemporâneos (CNPq/UFCG).
} 


\begin{abstract}
RÉSUMÉ
Cet article traite de la sociabilité des jeunes élèves médiatisée par les technologies numériques de l'information et de la communication, ainsi que de la manière dont ce nouveau mode de vie en ligne interfère dans les relations établies en contexte scolaire. Cette recherche de terrain a été réalisée dans les années 2018 et 2019 à partir d'une observation détaillée de la vie quotidienne des élèves d'un lycée public de l'État de Paraíba. Pour cela, nous avons sélectionné 73 interlocuteurs, 46 femmes et 27 hommes. L'analyse des données a révélé que des écarts se produisent entre les sociabilités des jeunes dans les réseaux numériques et les pratiques pédagogiques en milieu scolaire, stimulant les comportements de résistance des élèves envers les activités en face-à-face en classe, dans la même mesure que les jeunes expriment le désir que les cours hors ligne puissent être plus dynamique grâce à l'utilisation des technologies numériques.
\end{abstract}

\title{
MoTS-CLÉS
}

Technologies numériques; École; Jeunes étudiants.

\section{“EL USO DEL SMARTPHONE ES UN BUEN COMIENZO": ESTUDIO DE SOCIABILIDADES JUVENILES EN ESPACIOS ONLINE Y OFFLINE}

\section{RESUMEN}

En este artículo se analiza la sociabilidad entre los jóvenes estudiantes mediada por las tecnologías de la información y la comunicación digitales, así como cómo este nuevo estilo de vida online interfiere en las relaciones que se establecen en el contexto escolar. Esta investigación de campo se llevó a cabo en los años 2018 y 2019 a partir de una observación detallada de la vida cotidiana de los estudiantes de una escuela secundaria pública del estado de Paraíba. Para ello, seleccionamos 73 interlocutores, 46 mujeres y 27 hombres. El análisis de los datos reveló que se producen brechas entre las sociabilidades de los jóvenes en las redes digitales y las prácticas pedagógicas en el ámbito escolar, estimulando conductas de resistencia de los estudiantes hacia las actividades presenciales en el aula, en la misma medida que los jóvenes expresan deseos que las clases presenciales pueden Ser más dinámico mediante el uso de tecnologías digitales.

\section{PALABRAs CLAVE}

Tecnologías digitales; Colegio; Jóvenes estudiantes. 


\section{INTRODUÇÃO}

Aproxima-se das sete horas da manhã e os jovens começam a chegar na escola para enfrentar atividades pedagógicas que se estenderão até às dezessete horas. Ao longo da jornada de estudos, muitos serão os exercícios propostos pelos docentes, frente às diversas reações dos estudantes. Há os que aderem com sintonia às propostas apresentadas em muitos momentos e os que apresentam resistências. A longa jornada de quase dez horas na escola, onde inclusive realizam as refeições, estimula e possibilita muitas formas de interações entre os estudantes, assim como restringe outras. Nesse contexto, o acesso à internet é limitado, mesmo assim, pode-se observar uma turma de estudantes que se comunica a partir do uso de folha de caderno, sobre a qual cada interlocutor escreve ou desenha o que deseja comunicar. Assim, "imitando" as formas recorrentes de comunicação praticadas na plataforma digital WhatsApp ${ }^{3}$, eles fazem o papel circular no momento da aula presencial.

Proibidos de usar o smartphone $e^{4}$ durante as aulas para fins não pedagógicos, os jovens estudantes elaboram estratégias como essa para interagir entre eles, de maneira silenciosa. A proibição de fazer uso dos aparelhos digitais de comunicação durante as aulas limita sua utilização, mas não os impede. Vários são os estudantes, por exemplo, que pegam seus smartphones e tiram fotos das anotações feitas no quadro pelos professores. Através de tal atitude eles conseguem registrar o conteúdo copiado no quadro, e que de outra maneira levariam longos minutos e em alguns casos mais de hora para copiar em seus cadernos.

Nesse cotidiano escolar observado, muitas das atividades oficiais propostas se chocam com desejos e práticas dos jovens estudantes, especialmente com aquelas que emergem e ganham visibilidade a partir do uso de instrumentos digitais, a exemplo de smartphones.

Os fatos supracitados compõem amostras do dia a dia em uma escola pública de Ensino Médio de tempo integral, situada na cidade de Campina Grande, no interior do estado da Paraíba, onde realizamos a pesquisa que serve de base para a composição deste texto.

\footnotetext{
3 Significa "o que está havendo?". Trata-se de um aplicativo (programa de computador para processar dados) de mensagens instantâneas para enviar textos, áudios, vídeos curtos e fotos. Além disso, também pode ser utilizado tanto para realizar compras (por exemplo, serviços de delivery) quanto para trabalho (em grupo).

${ }^{4}$ Termo em inglês que significa "telefone inteligente". É usado para designar uma nova linhagem de telefones celulares que possuem uma série de tecnologias integradas no mesmo aparelho de acesso à internet. Em termos técnicos, a principal diferença para os aparelhos de comunicação sem a função smart seria o fato de não ter acesso à internet.
} 
Pesquisas realizadas sobre os impactos das chamadas Tecnologias Digitais de Informação e Comunicação, doravante TDICs, mostram bem como as tecnologias digitais têm provocado transformações nos ambientes escolares e "modificado as maneiras como os estudantes se relacionam com o saber e com o cotidiano escolar" (PEREIRA, 2017, p. 169). Entre outros fatores, o uso dos smartphones assinala novas possibilidades nas sociabilidades juvenis contemporâneas on-line, nas quais interferem diretamente em distintos ambientes sociais, como por exemplo, no contexto pedagógico presencial. A escola, por mais que se esforce para tentar impedir a influência desses "agentes" externos, da qual a proibição de uso dos smartphones é apenas uma situação específica, não tem conseguido blindar todos os espaços através dos quais essas influências penetram no espaço escolar. A própria tentativa de impedir o uso dos smartphones se apresenta como reconhecimento da presença das TDICs na escola. As tecnologias digitais não apenas estão presentes através de estudantes e professores, para falar apenas dos dois principais sujeitos coletivos que compõem esse ambiente pedagógico, como têm ajudado a reconfigurar as relações entre seus atores. A pesquisa desenvolvida por Pereira nas periferias da cidade de São Paulo demonstra bem como tal processo tem ajudado a criar campos de possibilidades e tensões nas escolas paulistas.

No contexto das sociabilidades on-line, parcelas significativas das juventudes contemporâneas se nutrem de expectativas de que a escola presencial incorpore o uso das tecnologias digitais, ajudando a tornar mais atrativas as atividades pedagógicas. As críticas ao modelo pedagógico não nascem com a presença das TDICs, evidentemente, mas ganham com sua presença novas críticas às formas pedagógicas tradicionais. Dessa forma, temos o contexto pedagógico presencial marcado por práticas pedagógicas e cognitivas de uma cultura letrada "tradicional" (GIRALDO, 2015) e, ao mesmo tempo, permeado pelas "novas" formas de ser, pensar, agir e aprender das juventudes contemporâneas (SIBILIA, 2015).

A escola na era das TDICs está permeada por perspectivas que devem ser consideradas. De um lado, jovens estudantes com inéditas subjetividades, por conta de suas "novas" linguagens apregoadas através das tecnologias digitais e, por outro, a escola que solicita dos seus estudantes modos específicos de comportamento e de aprendizagem que demandam, na maioria das vezes, silêncio e concentração por horas a fio na sala de aula.

Nessa pesquisa, investigamos como as novas sociabilidades on-line das juventudes no contexto das tecnologias digitais repercutem em uma escola pública presencial de Ensino Médio em regime de tempo integral. Este artigo objetiva compreender as dinâmicas de uso das tecnologias digitais e os novos estilos de vida das juventudes da atualidade, na medida que ajudam a produzir comportamentos que interferem nos processos pedagógicos dentro do ambiente escolar presencial. 
A pesquisa foi realizada nos anos de 2018 e 2019 na escola já referida. No início da pesquisa a escola contava com cerca de 550 estudantes, divididos em três séries. Optamos por estabelecer interlocuções, prioritariamente, com 73 estudantes da $1^{\text {a }}$ série, com faixa etária entre 13 e 17 anos, devidamente autorizados pelos pais, por eles mesmos, bem como pela autoridade institucional. A razão para a escolha desse grupo de estudantes se deve à constatação de que os estudantes recém-chegados ao Ensino Médio são os que mais "sofrem" (sono, insatisfação, tédio etc.) em meio a inserção nessa nova etapa escolar de tempo integral, em comparação com os estudantes das demais séries subsequentes. A escolha da escola pesquisada se deve, entre outros fatores, ao fato dela atender a mais de um terço dos bairros da cidade de Campina Grande, que conta com cerca de quatrocentos e dez mil habitantes, oferecendo assim amostra significativa para a realização da investigação.

No início da pesquisa de campo observamos o cotidiano escolar no "chão da escola" (PEREIRA, 2017), acompanhando as rotinas de estudantes dentro e fora das salas de aulas, com o objetivo de compreender o dia a dia desses jovens estudantes no conjunto de relações que esses estabelecem na internet, bem como com professores e funcionários da escola. Concomitantemente às observações, aplicamos questionários com 73 discentes.

Para o tratamento dos dados qualitativos (respostas abertas dos questionários) empregamos o software NVivo, que nos auxiliou nas análises de conteúdo (textos/falas), através da busca automática de palavras e de padrões léxicos, com o objetivo de compreender as opiniões e percepções do tema aqui em tela. Por análise de conteúdo, compreende-se, como um "conjunto de técnicas de análise de comunicações, cujo objetivo ultrapassa as incertezas e enriquece a leitura dos dados coletados imprimindo, [...], o rigor da objetividade, da cientificidade e a riqueza da subjetividade" (MOZZATO; GRZYBOVSKI; TEIREIRA, 2016, p. 581). Através das Nuvens de Palavras (diagrama com uma lista hierarquizada com as palavras mais frequentes), partimos do pressuposto de que as respostas dos sujeitos, observados durante a pesquisa de campo, representam suas ideias, ou seja, indicam aquilo que é desejável ou não em uma dada realidade social na qual eles interagem cotidianamente.

\section{JUVENTUDES NO CONTINUUM CULTURA DIGITAL-LETRADA}

Assinalar juventudes no plural, e não no singular, já denota que se trata de uma categoria heterogênea, multifacetada e complexa, principalmente quando nos deparamos com novas experiências e multiplicidades de interações sociais permeadas pelo uso das tecnologias digitais. No entanto,

"[...] reconhecer a diversidade da juventude não significa desistir do objeto de entender por que a modernidade criou a própria possibilidade de juventude. A criação das juventudes é um dos fundamentos da modernidade, e a existência da 
multiplicidade quase que incontrolável da juventude é um sinal de que este fundamento assim como outros fundamentos da modernidade, possui suas contradições" (GROPPO, 2000, p.18).

As demarcações e definições do que é ser jovem muda a cada contexto histórico, com reconfigurações nas maneiras de configurar as sociabilidades, pois, como observa (PEREIRA, 2016, p.16) no início de seu estudo, "juventude deve sempre ser definida como uma categoria relacional e contextual que não pode ser entendida isoladamente". Рara a realização da discussão aqui em foco, pensamos "juventudes" enquanto sinônimo de estudantes do Ensino Médio e a partir de um recorte de geração que no caso do grupo estudado tem entre 13 e 17 anos de idade. Ainda assim, pensar essa categoria histórica e dialeticamente consiste em ponderar o conjunto de relações que seus atores estabelecem com outros atores que compõem o ambiente escolar, mas também em considerar as relações que estabelecem entre eles, inclusive as mediadas pelas redes sociais virtuais.

A participação ativa das juventudes na $W e b^{5}$, ou seja, eles mesmos sendo protagonistas de uma gama de produção cultural digital, faz com que o uso, acesso e criação de práticas sociais através dos dispositivos digitais influenciem na constituição de suas sociabilidades. O acesso ao conteúdo da internet não representa apenas de um passatempo ou mero entretenimento, mas, sobretudo, práticas fundamentais para a construção das identidades de uma parte significativa das juventudes contemporâneas. As mídias digitais "vêm dando origem a processos de aceleração, pulverização e mistura de experiências que atingem os sujeitos de modo complexo e, muitas vezes, desestabilizador" (ALMEIDA, 2006, p. 142-143). Assim, "[...] o uso dos dispositivos digitais reconfigura os contextos culturais dos jovens, oferecendo, assim, novas possibilidades de participação inexistentes até há alguns anos" (GIRALDO, 2015, p. 172). Desse modo, as TDICs influenciam (mas não determinam) nos modos das pessoas se relacionarem umas com as outras, comprometendo não apenas as emoções e as consciências individuais, mas também as sociabilidades.

Nesse sentido, a cultura digital interfere numa relação simbiótica com cada indivíduo, na constituição das subjetividades, especialmente entre as juventudes, principais usuárias das tecnologias digitais. A antropóloga (SIBILIA, 2012, p. 89) ressalta que uma das marcas trazidas pelo uso das TDICs é que os usuários das tecnologias digitais mudam rapidamente as telas de imagens dos aparelhos portáteis de acesso à Web e que "as imagens que povoam nossas paisagens costumam nos impactar com estímulos estilhaçados". No entanto, o acesso ao conteúdo da internet não se faz apenas no campo do entretenimento. O uso de smartphone para fotografar o conteúdo no quadro é um bom exemplo dessas

\footnotetext{
${ }^{5}$ Expressão inglesa que significa rede ou teia. Trata-se de uma rede mundial de computadores interconectados que estendeu seu alcance ao público em geral, principalmente a partir dos anos de 1990.
} 
diversas possibilidades de utilização das tecnologias nas quais constituem a cultura denominada de digital.

Рara as análises que se seguem neste artigo entendemos por cultura digital um conjunto de conhecimentos, linguagens, habilidades e interações sociais vivenciadas no âmbito das tecnologias digitais de informação e comunicação, que por ser definida "como o conjunto de práticas e valores ligados ao desenvolvimento de novas formas de sociabilidade dentro de um ambiente midiático digital" (GIRALDO, 2015, p. 161). Essas interações sociais por meio das TDICs se fazem a partir das performances dos seus usuários. No caso das juventudes, seus modos de comportamento vão depender, entre diversos fatores, dos múltiplos contornos cognitivos constituídos nos ambientes virtuais e da junção desses com práticas relacionais off-line, como é o caso do recorte dessa pesquisa - o contexto escolar.

Uma das principais práticas características da escola presencial consiste em manter estudantes por muitas horas dentro da sala de aula, com "[...] rotinas idênticas e progressivas se repetem em tais condições, com frequência diária e durante longos períodos da vida de cada sujeito. Não se deve subestimar a importância desse treinamento corporal, tão metódico [...]" (SIBILIA, 2012, p. 28). No entanto, por conta da incorporação das TDICs no cotidiano dos jovens da atualidade, as práticas sociais e cognitivas de uma cultura letrada passaram a ser comparadas com a fluidez cognitiva apregoada pelas tecnologias digitais, tão largamente experimentadas pelos estudantes. Com a intensificação do uso das tecnologias digitais na vida diária dos estudantes, a formação escolar está muito distante dessa nova realidade social e cognitiva, pois, "[...] para os jovens, a aprendizagem adquirida nesta esfera não tem repercussão de maneira direta no uso cotidiano e em muitos aspectos não é considerada útil" (GIRALDO, 2015, p. 164).

Esses "novos" modos de aprender juvenis nem sempre encontram sintonia com as práticas cognitivas de uma cultura letrada. No entanto, no contexto das TDICs, o conhecimento é gerado de forma mais eficaz quanto permeado pela simulação, gamificação e atividades lúdicas, pois, o conhecimento por simulação, com o uso de jogos é uma tecnologia intelectual e "[...] funciona mais como um módulo externo e suplementar para a faculdade de imaginar" (LÉVY, 1993, p. 125). Assim, as "novas" subjetividades das juventudes contemporâneas funcionam de maneira mais eficaz através do lúdico e do dinamismo cognitivo proposto pelos ambientes digitais de comunicação e informação.

No contexto das TDICs, as "mentes distraídas" (numa perspectiva voltada à lógica da cultura escolar tradicional) querem se divertir, esperam que as aulas sejam mais "dinâmicas". Essa busca por aulas mais lúdicas pode ser vista como uma forma de resistência frente às práticas de uma cultura letrada, nas quais exigem certo tipo de concentração, silêncio, leitura e interpretação, enquanto que “[...] a dimensão lúdica envolve desafio, surpresa, 
possibilidade de fazer novo, de querer superar obstáculos iniciais [...]" (SMOLE; DINIZ; PESSOA; ISHIHARA, 2008, p. 10).

\section{A ESCOLA PRESENCIAL NO CONTEXTO DAS TECNOLOGIAS DIGITAIS}

O recorte temporal da presente pesquisa nos permitiu constatar que a escola em tela funciona de segunda-feira à sexta-feira, em tempo integral, das 7 h30 às $17 \mathrm{~h}$. Diariamente, no momento da entrada dos estudantes, há momentos de acolhimento, organizados por eles mesmos, na maioria das vezes formando um corredor no portão principal da escola com músicas, brincadeiras e descontração. Posteriormente, os estudantes se dirigem para as salas de aula, de acordo com a aula e o horário previamente estabelecidos. Entre uma aula e outra eles trocam de sala, pois, nesse modelo de ensino, as turmas não têm sala fixa. Com base nas informações das diretrizes operacionais para as escolas de tempo integral paraibanas (PARAÍBA, 2016), constatamos que os estudantes precisam frequentar a escola 5 dias por semana, com 9 aulas por dia, tendo que cumprir com uma carga horária anual de $1.845 \mathrm{~h}$ por série para concluir o Ensino Médio.

No universo empírico analisado, os 73 jovens estudantes pesquisados tinham entre 13 e 17 anos de idade, sendo as mais frequentes de 15 e 16 anos $(61,6 \%$ e 23,3\%, respectivamente). A maioria do gênero feminino (63\%), grande parte se declarou da raça negra (preta e parda: 64,3\%), 26\% disseram ser de cor branca e a minoria amarela (4,1\%). 64 estudantes moram na zona urbana e 7 na zona rural ( $87,7 \%$ e $9,6 \%$, respectivamente). Ao analisarmos a renda das famílias dos estudantes pesquisados, verificamos que $37 \%$ têm renda per capita mensal entre 1 e 2 salários-mínimos, 24,7\% entre 2 e 3 salários-mínimos, 23,3\% até 1 salários-mínimos e 2,7\% têm renda acima de 5 salários-mínimos. Sendo assim, $61,1 \%$ dos pais/responsáveis pelos estudantes participantes dessa pesquisa vivem com até 2 salários-mínimos mensais. Estes dados mostram, entre outros aspectos, uma composição heterogênea dos casos aqui analisados no que diz respeito aos aspectos socioeconômicos.

O uso intenso dos aparelhos portáteis de comunicação é uma das principais marcas visíveis dos comportamentos das juventudes contemporâneas. Através das TDICs são constituídas as amizades, prestígio, status social e aceitação dentro do grupo social. Os dados da presente pesquisa mostram que em média os jovens ficam longas horas por dia na internet, divididas da seguinte maneira: 4 horas nas redes digitais como Facebook, ${ }^{6}$

\footnotetext{
${ }^{6}$ Uma tradução literal de Facebook pode ser "livro de caras". É uma rede social virtual lançada no ano de 2004 em que os usuários postam comentários, compartilham fotos e vídeos.
} 
Instagram ${ }^{7}$ e WhatsApp e em média 2 horas em jogos on-line. Dentro da escola, o tempo médio de acesso à internet fica restrito à, no máximo, 2 horas por dia.

A maioria dos estudantes pesquisados, 97,3\%, usam o smartphone como principal meio de acesso à internet. Ainda assim, destes, 68,5\% acessavam à internet na maioria das vezes quando estavam em casa e apenas 6,8\% não possuíam meios de acesso à Web em seu domicílio. Nesses últimos casos, os acessos ao mundo virtual ficavam restritos aos espaços que disponibilizavam internet gratuita, como shoppings, escola, casas de familiares e de amigos etc. Outra informação importante é que lazer e construção de maior círculo de amizades são as principais motivações para o uso dos smartphones (61,6\% e 19,2\%, respectivamente) por parte dos jovens participantes da pesquisa. WhatsApp, Instagram e Facebook foram os mais citados pelos esses estudantes $(57,5 \%, 32,9 \%$ e 4,1\%, sequencialmente) como os principais canais de troca de mensagens utilizados por eles. A preferência por essas redes sociais se deve, entre outros fatores, ao fato delas não "exigirem" comentários nas publicações ou comentários mais longos (na maioria das vezes utiliza-se apenas (ikes), sendo mais recorrente o uso de emoticons e de palavras com abreviaturas. No entanto, apenas $5,5 \%$ dos estudantes declararam que acessam à Web para auxiliar nos estudos escolares. Com relação ao tempo de uso da internet, feito em casa, depois de passar o dia na escola, a maioria dos estudantes $(54,8 \%)$ disse que passam entre 1 e 3 horas na internet, 34,2\% entre 3 e 5 horas e 8,2\% menos de 1 hora por dia na Web, utilizando uma parte significativa do tempo para lazer e entretenimento.

A prática de uso dos smartphones pelos jovens estudantes não é diferente no espaço escolar presencial. No contexto pedagógico pesquisado, a maioria dos estudantes possui esse equipamento digital, mas ele permanece pouco utilizado para fins pedagógicos. Nesse ínterim, constatamos que ter o smartphone não era garantia de acesso à internet, pois a maioria dos estudantes observados $(90,4 \%)$ acessam às redes digitais apenas quando estavam em casa, enquanto 5,5\% têm condições financeiras de viabilizar o acesso à Web em qualquer lugar através da tecnologia 3G ou 4G, garantindo "maior liberdade" de navegação no mundo virtual.

Estas informações mostram, entre outras questões, que os estudantes ficam privados de acessar às redes virtuais quando estão na escola, causando uma espécie de "nomofobia", ao contrário do livre acesso à internet que encontram em outros ambientes.

\footnotetext{
${ }^{7}$ Significa "câmera instantânea". Trata-se de uma rede social on-line de compartilhamento de fotos e vídeos entre os seus usuários. Uma das suas principais características é que cada perfil pode acompanhar a quantidade de curtidas e comentários em cada postagem.

${ }^{8}$ Está relacionado ao medo de ficar sem celular, smartphones, computadores e videogames. A OMS (Organização Mundial da Saúde) define esta adicção como doença, em decorrência das últimas transformações tecnológicas que afetam os comportamentos de uma parte significativa da sociedade contemporânea.
} 
Essa limitação de acesso à internet no espaço escolar pode ser apontada, embora não exclusivamente, como uma das razões para a emergência de sentimentos de impaciência e insatisfação com a rotina escolar, potencializando conflitos, especialmente nos espaços da sala de aula.

Em geral, o uso compulsivo das TDICs afeta diretamente a multitarefa, o humor e o estresse das pessoas. Em consequência dessa dependência emocional com os aparelhos de comunicação digitais, os usuários dos ambientes virtuais consideram diminuída suas capacidades de atenção e de paciência frente às relações face a face, em detrimento de um mundo digital caracterizado, prioritariamente, pela aceleração das informações, microatenção e microconversa. Quando a velocidade do fluxo de informações é muito baixa ou lenta ou entediante (principalmente entre as juventudes contemporâneas), ou "quando a saturação chega a certo nível de esgotamento, ele [usuário de aparelhos digitais de comunicação] se entedia e se desliga" (SIBILIA, 2012, p. 89). Nesse sentido, a realidade dos meios midiáticos da internet tem causado problemas nos aspectos cognitivos entre muitos jovens estudantes, pois, "“pensar é cansativo", "pensar é chato", "pensar é perigoso", máximas do senso comum que demonstram a atrofia do pensamento em uma realidade social obtusa" (BITTENCOURT, 2013, p. 21).

\section{Imagem 1: Estudante copiando conteúdo em sala de aula com o uso do smartphone.}

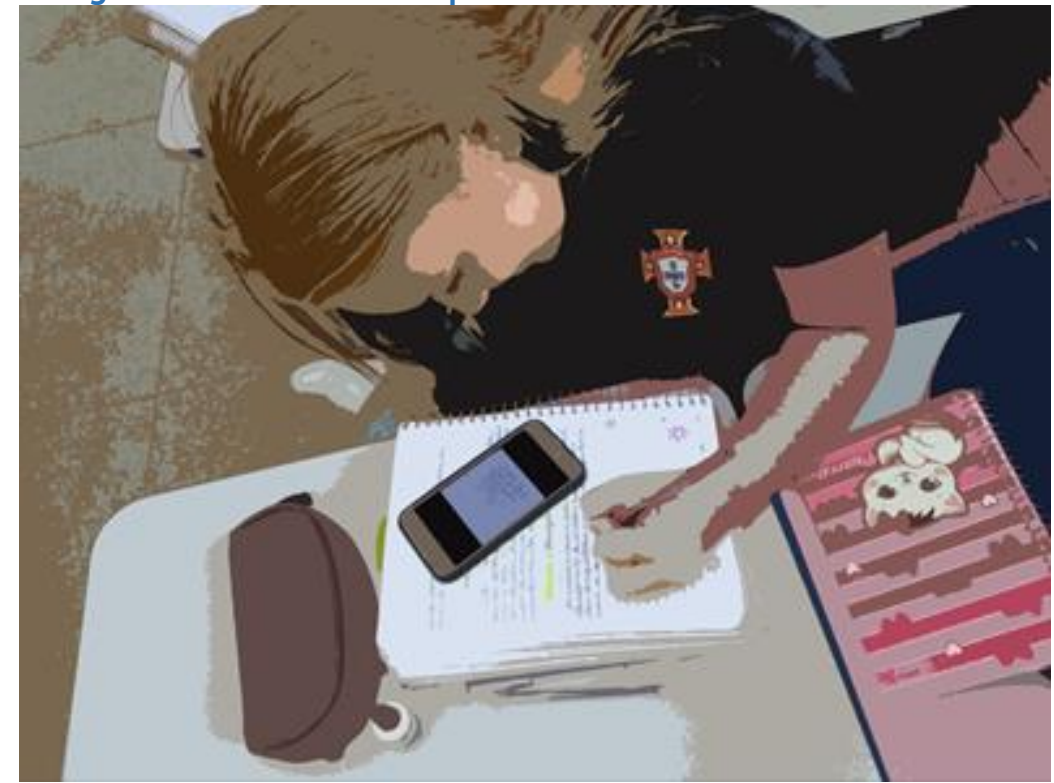

Fonte: pesquisa de campo (2019).

Nesta pesquisa realizada junto aos estudantes constatamos, por exemplo, a recorrência do uso dos smartphones para copiar textos e exercícios colocados pelos professores na lousa da sala de aula (Imagem 1). Dessa forma, estudantes "tiram" fotos das anotações que os professores fazem na lousa e depois anotam no caderno, olhando apenas 
para a imagem registrada no smartphone ou iphone ${ }^{9}$. Essa prática indica, entre outras, que os corpos também sofrem influência e estão sendo moldados a partir das perspectivas criadas pelas mídias digitais. O fato de ficarem sentados nas carteiras olhando para a lousa ou assistindo aula causa uma série de desconfortos, levando-os a recorrerem aos aparelhos digitais para realizarem anotações no caderno ou exercício escolar. Assim, a cabeça curvada para baixo e as imagens dos aparelhos digitais são mais confortáveis para os estudantes do que ficar no encosto firme das carteiras da sala de aula, olhando para frente o tempo todo e tendo que se concentrar na aula. Entretanto, não podemos esquecer que mais do que posturas corporais diferentes, os estudantes parecem apontar para o incômodo com algumas práticas pedagógicas tradicionais.

Na imagem 2 abaixo, registramos duas folhas de caderno que uma turma utilizou para dialogar dentro da sala de aula. Isso aconteceu em virtude de um professor ter proibido os estudantes de conversarem durante a aula, fazendo com que eles passassem a se comunicar utilizando a mesma lógica da estrutura e linguagem do WhatsApp, aplicativo de conversação largamente utilizado pelos jovens estudantes. Frases curtas e desenhos de imagens foram alguns dos recursos usados para dialogar na sala de aula, como se pode ver na imagem abaixo.

\section{Imagem 2: Folhas de caderno usadas para conversar na sala de aula.}

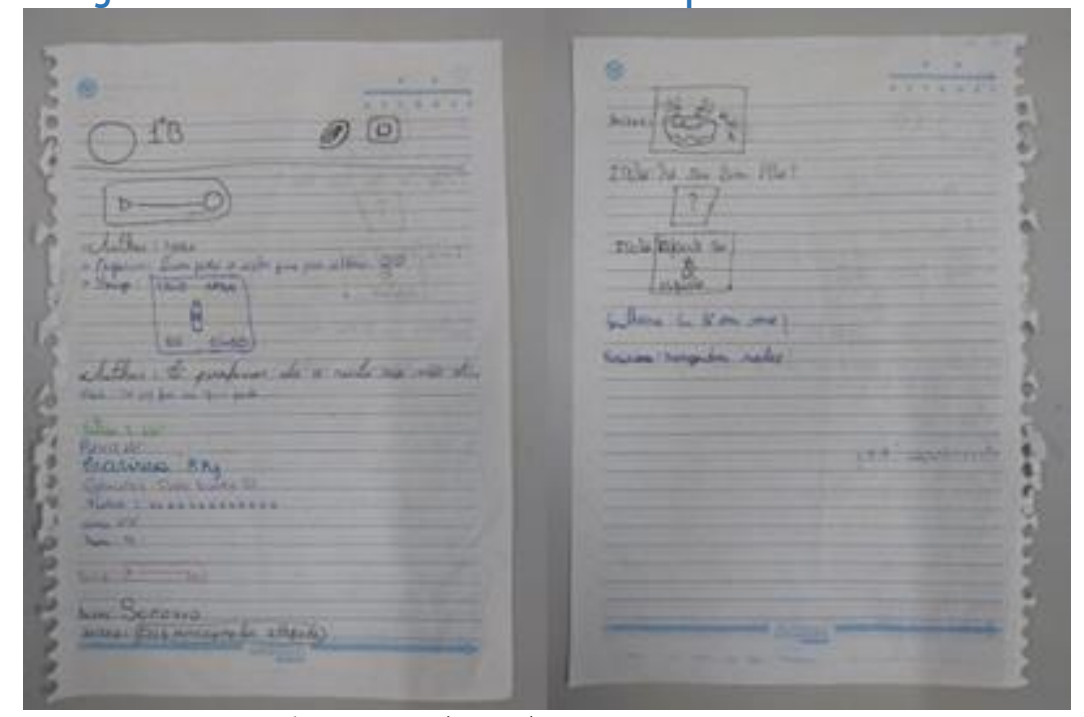

Fonte: pesquisa de campo (2019).

Esse comportamento pode ser considerado como resistência às imposições da autoridade pedagógica. Fazer uso da folha para tal finalidade é uma estratégia no seio das relações de poder, principalmente entre os "dominados". Nesse sentido, os discursos ocultos se processam em condições diferentes dos discursos públicos, pois, "[...] este discurso oculto

\footnotetext{
${ }^{9}$ É um modelo de smartphone fabricado pela Apple. Em geral, tem o preço mais elevado em comparação com aparelhos de outras marcas e é considerado como sinônimo de maior status social também entre os jovens aqui observados.
} 
colectivo es esencial en cualquier imagen dinâmica de las relaciones de poder" (SCOTT, 2000, p. 69).

Tais transformações no campo da comunicação e interação humana tem sido um dos fatores sociais que influenciam, nas dinâmicas de funcionamento de várias instituições, entre elas a escola. Nesse sentido, "é preciso que a instituição escolar prepare a população para um funcionamento da sociedade cada vez mais digital e também para buscar no ciberespaço um lugar para se encontrar, de maneira crítica, com diferenças e identidades múltiplas" (ROJO, 2013, p. 7). Isso significa que a escola enfrenta agora novos desafios: inserir novas competências e habilidades tanto cognitivas quanto pedagógicas condizentes com os novos modos de ser e aprender dos jovens estudantes contemporâneos.

As observações realizadas durante a pesquisa de campo na escola nos fizeram perceber como os jovens estudantes têm disposições cognitivas voltadas para aprender de maneira lúdica, dinâmica e com o uso de smartphones. Na Figura 1, temos uma representação do conjunto de respostas dos 73 estudantes sobre suas percepções das possibilidades de gostarem de estudar na escola de modo presencial.

Figura 1: Nuvem de palavras para o nó "motivação para gostar de estudar na escola"

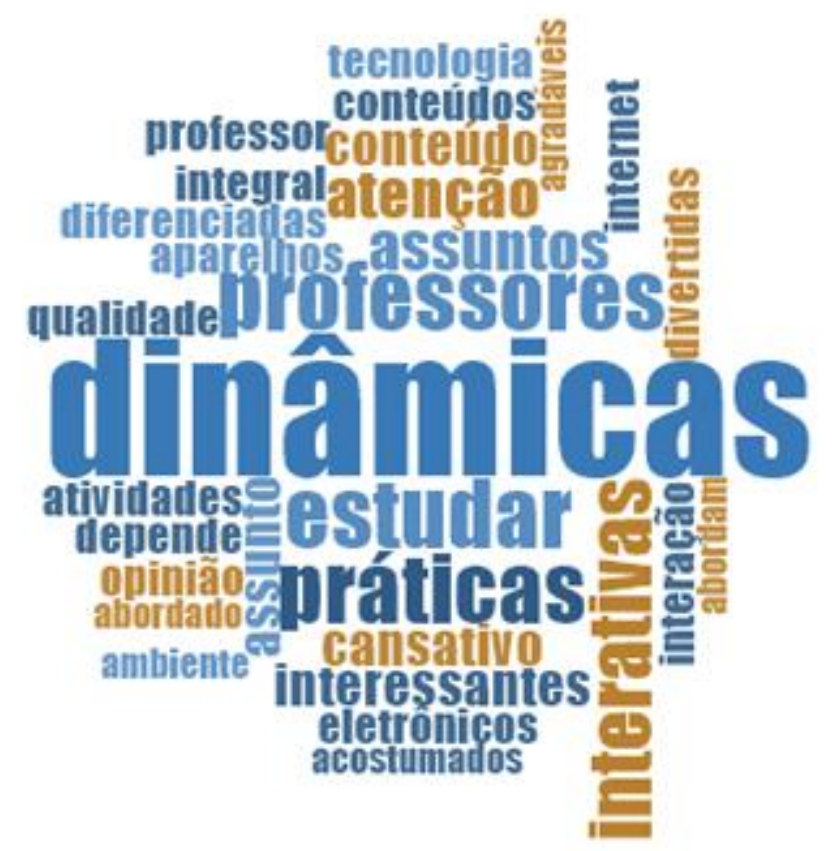

Fonte: elaboração dos autores (2019).

No conjunto de respostas, constatamos que o termo "dinâmica" está na centralidade da figura acima, por ser o mais recorrente em suas falas, seguido das palavras mais frequentes como "estudar", "práticas" e "interativas". Esses dados quantitativos sugerem entre outros aspectos que os estudantes desejam que as aulas sejam compatíveis com as novas subjetividades e interações praticadas em ambientes virtuais, ou seja, que sejam mais lúdicas. Nesta situação, eles se referem às possibilidades das aulas serem 
realizadas, por exemplo, em espaços abertos (fora da sala de aula), com brincadeiras, jogos, músicas e principalmente com as tecnologias digitais que possam estimulá-los a estudar de forma prazerosa dentro do ambiente escolar. Em outras palavras, os estudantes não estão rejeitando a cultura letrada nem exigindo mudança para o mundo virtual, mas a construção de pontes que possam interligar esses dois ambientes. Portanto, não se trata necessariamente de manifestações contrárias ao universo escolar e nem de crítica à escola em si, mas aos métodos e práticas pedagógicas que em alguns momentos se situam distantes do universo juvenil da atualidade.

Em suas declarações sobre as formas pedagógicas mais envolventes, identifica-se que há uma tendência de defesa para que os conteúdos trabalhados em sala de aula sejam "mais divertidos", "diferenciados" e "mais dinâmicas e interativos". A utilização de tecnologias digitais seria mais atrativa e "estimularia os estudantes a estudar melhor". Рara um dos estudantes participantes dessa pesquisa, "o uso do smartphone é um bom começo", ao se referir e desejar possíveis inovações pedagógicas com uso das tecnologias digitais. Não é por acaso que tais anseios emergem no cenário pesquisado, pois a maioria das aulas $(68,8 \%)$ eram realizadas através de aulas expositivas e dialogadas e apenas em $9,4 \%$ das aulas os professores utilizam as tecnologias digitais para fins pedagógicos.

Estas disposições lúdicas e cognitivas com uso das TDICs por parte dos estudantes pesquisados para aprender dentro da escola de maneira mais prazerosa são evidenciadas também através da síntese de suas respostas, representada na Figura 2. Ao serem indagados sobre como as aulas na escola de tempo integral poderiam se tornar mais atrativas, eles indicaram que elementos de ludicidade poderiam estar mais presentes, ajudando a tornar o ambiente da sala "menos pesado". Observe-se que o termo "brincadeiras" está na centralidade dessa imagem, onde aparecem outras palavras com mais frequência, tais como "informática", "tecnologia", "diferentes" e "computadores". A partir dessas informações percebemos que há uma expectativa de que aulas sejam realizadas através de "brincadeiras" para que consigam compreender de modo mais eficaz os assuntos abordados na sala de aula. 
Figura 2: Nuvem de palavras para o nó "aulas mais dinâmicas"

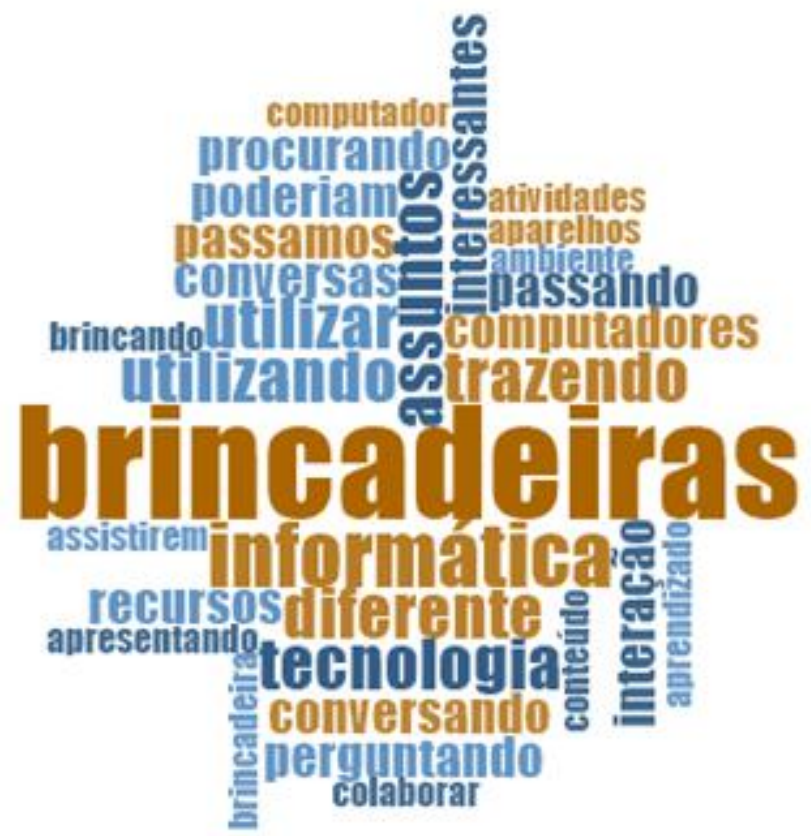

Fonte: elaboração dos autores (2019).

O termo "brincadeiras" surge nesse contexto como sinônimo de diversão, leveza, sem conotação de ausência de seriedade, como uma leitura apressada e descontextualizada poderia levar a pensar. Dentre os 73 estudantes participante da pesquisa, 42,46\% afirmaram que as aulas seriam mais dinâmicas se fossem realizadas através de brincadeiras e uso das tecnologias digitais e isso os ajudaria a compreender e assimilar os assuntos escolares melhor do que na atualidade, já que 30,13\% dizem que aula dinâmica é aquela na qual o professor e os estudantes utilizam as TDICs como recursos técnicos/pedagógicos.

Os contextos pedagógicos da atualidade não parecem propiciar aos estudantes de situações de aprendizagem que despertem o interesse pelos estudos dentro da escola, pois, na maioria das vezes, as formas de aprender no cotidiano das tecnologias digitais são distintas dos modos de ensinar no ambiente escolar presencial, como já visto ao longo de nossa análise. Nesse sentido, o sociólogo (SILVA, 2014, p. 27) destaca que as maneiras de aprender no dia a dia "envolvem movimentos endógenos, involuntários, inconscientes, amorfos, casuais (fortuitos), indiretos. Já os aprendizados desenvolvidos em contexto escolar são exógenos, conscientes, sistemáticos, explícitos, estruturados, orientados", ao citar os estudos de Cope e Kalantzis. Já (MORAN, 2018, p. 3), ao abordar as relações e contradições entre as novas formas de aprender e o ambiente escolar presencial, aponta que "os processos de aprendizagem são múltiplos, contínuos, híbridos, formais e informais, organizados e abertos, intencionais e não intencionais". Dessa forma, o contexto pedagógico deve se relacionar com outros ambientes e formas de aprender condizentes com as necessidades das juventudes contemporâneas. 


\section{CONSIDERAÇõES}

As maneiras de ensinar e de aprender de modo eficiente dentro dos muros da escola sempre foram desafios enfrentados pelos pesquisadores e professores no tocante aos processos educativos em cada geração. Por isso, faz-se necessário compreender as peculiaridades das sociabilidades on-line das juventudes contemporâneas, bem como das novas formas de aprender, para que o ambiente de aprendizagem presencial possa se constituir como ambiente vivo, ou seja, capaz de gerar interesses junto aos estudantes. Nessa direção, é importante reconhecer que à internet é uma ferramenta singular para o estabelecimento de novas formas de interações sociais e constituição das juventudes contemporâneas. Nesse contexto, a escola ganha uma oportunidade de construir ambientes nos quais essa criatividade possa ser incorporada não como agente externo e ameaçador, mas como parte constituinte de um universo de ensino e aprendizagem no qual a figura do professor e do material didático impresso ganhem novas possibilidades e "auxiliares" nesse processo de construção e de transmissão do conhecimento científico.

Do ponto de vista cognitivo, conclui-se que as subjetividades das juventudes contemporâneas na era das tecnologias digitais não são apenas receptoras dentro do processo de ensino-aprendizagem, pois elas parecem se conectar de modo mais eficaz através de mensagens e imagens disseminadas através das telas de computadores e dos smartphones. Ocorre que as práticas pedagógicas do ambiente escolar preconizadas pela memorização, atenção e silêncio exigem dos estudantes um conjunto de habilidades emocionais e cognitivas que devem ser ajustadas às disciplinas dos seus corpos e subjetividades para se manterem dispostos a "aprender" ao longo de várias horas dentro dos muros da escola. Ao assistir aulas expositivas e dialogadas, ler livros didáticos e escrever/resolver atividades em cadernos, os jovens estudantes desenvolvem uma prática cognitiva (de forma linear, ascendente e acumulativa) distinto dos aspectos mentais preconizados pelo uso das tecnologias digitais. A cultura digital é caracterizada pela rápida saturação cognitiva, raciocínio assistemático (que não quer dizer desorganizada) e pela comunicação através de imagens de telas das tecnologias digitais enquanto a cultura letrada é preconizada pela concentração, memorização, raciocínio sistemático e pela comunicação oral. Assim, o processo de continuum entre cultura letrada-digital é permeado pelos conflitos e tensões, mas também pelas adaptações e permanências nos modos de comportamentos e sociabilidades das juventudes contemporâneas.

A retomada das aulas presenciais trará grandes desafios no contexto pós-ensino remoto síncrono e assíncrono em razão da pandemia da COVID-19. Nesse provável cenário o ensino poderá ter caráter híbrido, combinando elementos do ambiente off-line (contato com professores) com outros comuns ao ambiente on-line (uso das TDICs). Será que nesse 
hipotético cenário pós-pandemia a escola se tornaria mais atrativa para os jovens estudantes que não precisariam cumprir carga horária exaustiva dentro do ambiente escolar presencial para concluir os seus estudos? A pandemia trouxe impactos para a educação cujas consequências ainda estamos longe de poder dimensionar em toda a sua extensão. Por ora, podemos observar que a pandemia jogou luzes sobre as desigualdades de acesso à internet, principalmente entre a população mais jovem (e pobre). O que será o "novo normal" no campo educacional? Como os ambientes on-line e off-line serão redimensionados nos tempos vindouros? Em que grau e medida as sociabilidades on-line das juventudes contemporâneas irão continuar a interferir no contexto pedagógico?

\section{REFERÊNCIAS}

ALMEIDA, Maria Isabel Mendes de. "Zoar" e "ficar": novos termos da sociabilidade jovem. In: ALMEIDA, Maria Isabel Mendes de. EUGÊNIO, Fernanda (Orgs.). Culturas jovens: novos mapas de afeto. Rio de Janeiro: Zahar, 2006. p. 139-157.

BITTENCOURT, Nunes. 0 espetáculo não pode parar? Revista Filosofia, Ciência \& Vida. Ano VII, n. 88, p. 20-21, 2013.

GIRALD0, Diana. A aprendizagem e a participação social dos jovens adultos por meio do uso dos dispositivos digitais da Web. In: LOPES, Vanderlei Veget Cassiano. Tecnologia e sociedade: configuração, reconfiguração. Goiânia: Media Lab/ Ciar UFG/ Gráfica UFG, 2015. p. 157-177.

GROPPO, Luis Antonio. Juventude. Ensaios sobre Sociologia e História das Juventudes Modernas. Rio de Janeiro: Difel, 2000.

LÉVY, Pierre. As tecnologias da inteligência: o futuro do pensamento na era da informática. Tradução de Carlos Irineu da Costa. Rio de Janeiro: Ed. 34, Coleção TRANS, 1993.

MORAN, José Manuel. Metodologias ativas para uma aprendizagem mais profunda. In: BACICH, Lilian. MORAN, José. Metodologias ativas para uma educação inovadora: uma abordagem teórico-prática. Porto Alegre: Penso, 2018. p. 1-25.

MOZZATO, Anelise Rebelato; GRZYBOVSKI, Denise; TEIXEIRA, Alex Niche. Análises qualitativas nos Estudos organizacionais: as vantagens no uso do software Nvivo®. Revista Alcance, Eletrônica, v. 23, n. 4, p. 578-587, 2016.

GOVERNO DO ESTADO DA PARAÍBA. Diretrizes Operacionais para o Funcionamento das Escolas da Rede Estadual de Ensino. 2016.

PEREIRA, Alexandre Barbosa. "A maior Zoeira" na escola. Experiências juvenis na periferia de São Paulo, São Paulo: Editora Unifesp, 2016.

Do controverso chão da escola às controvérsias da etnografia: aproximações entre antropologia e educação, Horizontes Antropológicos, Porto Alegre, v. 23, n. 49, p. 149-17, 2017. 
ROJO, Roxane (Org.). Escola conectada: os multiletramentos e as TICs. São Paulo: Parábola, 2013.

SCOTT, James C. Los dominados y el arte de la resistência: discursos ocultos. Colección Problemas de México. Ediciones Era, 2000.

SIBILIA, Paula. Redes ou paredes: a escola em tempos de dispersão. Tradução de Vera Ribeiro. Rio de Janeiro: contraponto, 2012.

SIBILIA, Paula. 0 homem pós-orgânico: a alquimia dos corpos e das almas à luz das tecnologias digitais. Rio de Janeiro: Contraponto, $2^{\mathrm{a}}$ edição, 2015.

SILVA, Marco. Sala de aula interativa: educação, comunicação, mídia clássica.... São Paulo: Edições Loyola, $7^{a}$ ed., Coleção práticas pedagógicas, 2014.

SMOLE, Kátia Stocco; DINIZ, Maria Ignez; PESSOA, Neide; ISHIHARA, Cristiane. Cadernos do Mathema Ensino Médio. Volume 3 - Jogos de Matemática de $1^{\circ}$ a $3^{\circ}$ Ano. Porto Alegre: Penso, 2008.

Recebido em 29 de janeiro de 2021. Aprovado em 05 de agosto de 2021. 